\title{
The Sex Difference in Dimensional Communalities in Macaca nemestrina
}

\author{
STANLEY M. GARN, DARIS R. SWINDLER AND PAUL E. MINNIS \\ Center for Human Growth and Development, The University of Michigan, \\ Ann Arbor, Michigan 48104 and Department of Anthropology, \\ The University of Washington, Seattle, Washington 98195
}

\author{
KEY WORDS Sex differences - Communalities - Cranio-facial \\ dimensions - Sex-chromosomal regulation - Macaca ' Monkey.
}

\begin{abstract}
Intra-individual correlations for cranial, mandibular and dental measurements made on lateral skull radiographs of Macaca nemestrina were systematically higher in 30 adult females than in 31 adult males by an average of 0.11 to 0.15 , depending upon method of computation. Clearly, for the adult pig-tailed monkey as in Homo during both prenatal and postnatal life, developmental and dimensional communalities are systematically higher in the female indicating a general principle or trend.
\end{abstract}

From the early prenatal period through to full adult size, the human female enjoys greater communality in both dimensional and developmental events. This is true even in the embryo, wherein dental and skeletal development evidence systematically higher correlations in females as contrasted with males (Burdi et al., '74). This is true for the crown dimensions of the permanent teeth, wherein mesiodistal diameters of girls show higher intra-individual correlations than do the corresponding crown diameters in boys (Garn et al., '65). This is true in postnatal ossification timing of hand-wrist centers (Garn et al, '67), for postnatal nuclei of the foot (Garn and Rohmann, '66a,b) and for 77 postnatal ossification centers of the axial and appendicular skeleton (Garn et al., '66).

As shown in 61 sexually-mature, breeding-age pig-tailed monkeys (Macaca nemestrina) greater female dimensional communality also appears to be a characteristic of these old-world primates as well. Measurements of endocranial size, skull thickness, mandibular corpus and ramus size and both tooth-bearing and non-toothbearing bone all show systematically higher intra-individual correlations in $30 \mathrm{fe}$ male nemestrina monkeys than in a nearly identical number of 31 males.

Now the measurements were made on standardized lateral-skull radiographs, of anesthetized, living monkeys, using a
Helios dial-reading caliper with $0.05 \mathrm{~mm}$ readout and rms measuring accuracy of $\pm 0.15 \mathrm{~mm}$. The 16 measurements $(13$ of them pictured in fig. 1) were selected to include indications of brain dimensions, thickness of skull and browridges, size of the ramus, size of the mandibular corpus, symphyseal height and a selection of vertical measurements at the level of $\mathrm{M} 1$, including both tooth and bone (and height of crown and root, both separately and together).

For each sex, the full matrix of interdimensional correlations was calculated, yielding 120 correlations [i.e., $\frac{\mathrm{N}(\mathrm{N}-1)}{2}$ ], and therefore 120 pairs of correlations for comparison. Correlations were also grouped, according to the 16 measurements (ridge thickness, endocranial length, root height, etc.) to ascertain whether particular dimensions differed from the general trend. Comparisons therefore included (1) 120 pairs of sex-specific correlations and (2) intra-individual correlations grouped by measurement.

As shown in figure 2, corresponding correlations (browridge vs endocranial length, etc.) proved higher in adult female pig-tailed monkeys than in adult male monkeys of the same genus and species. This was the case for 96 of the 120 paired correlations shown above the isoequivalent or $\mathrm{Y}=\mathrm{X}$ line, a trend highly significant 


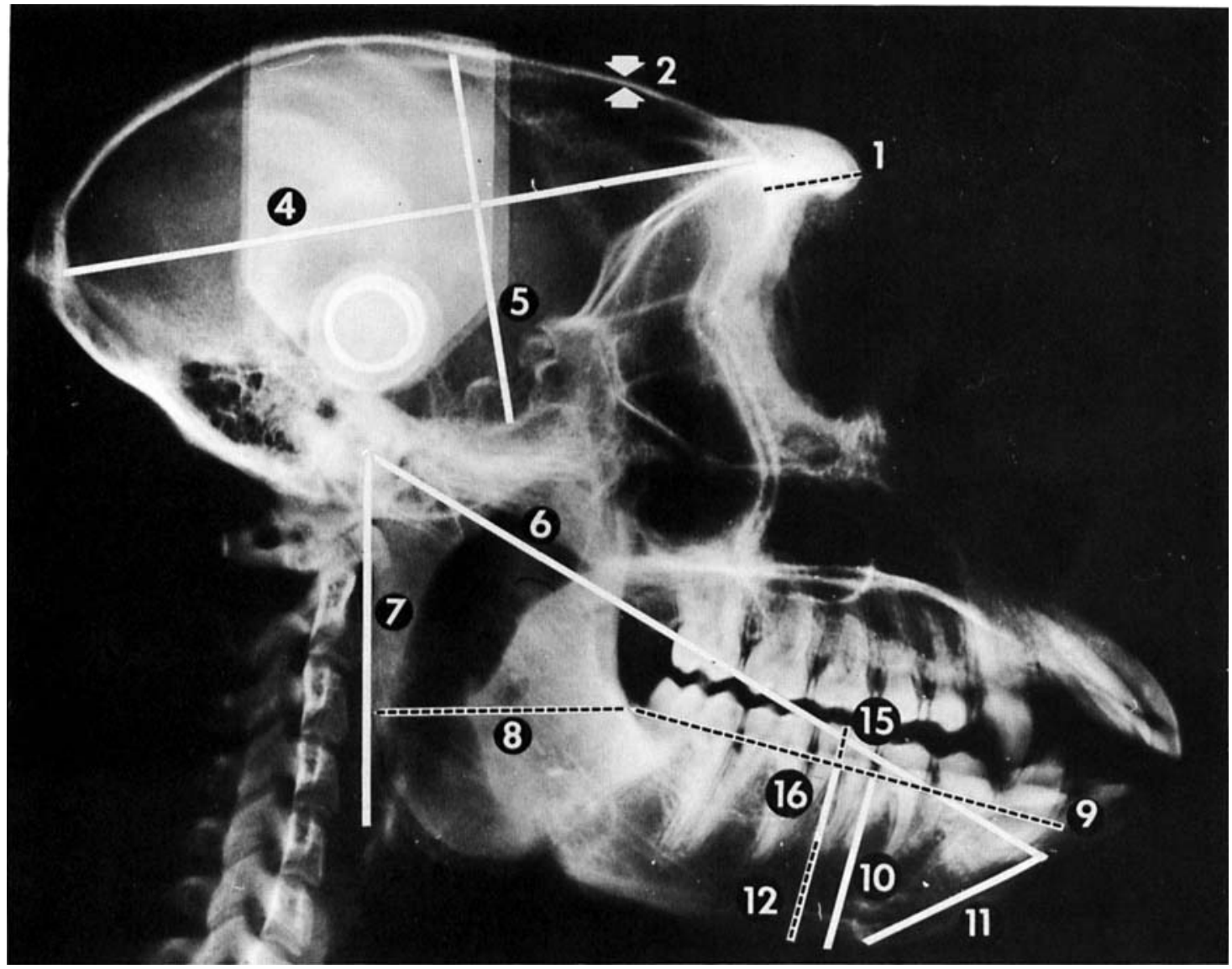

Fig. 1 Lateral-skull radiograph of a Macaca nemestrina adult showing the radiogram metric measurements of endocranial size, skull and ridge thickness. mandibular dimensions. and vertical dimensions of the teeth and supporting bone listed in table 1. Measurements 3 . 13. and 14 not shown separately.

by sign test, as against the $60: 60$ or chance hypothesis. Overall, intra-female dimensional correlations in Macaca nemestrina exceeded the corresponding male dimensional inter-correlations by 0.15 , a difference again highly significant using tests for the significance of the differences between matched pairs. While the 16 direct or subtractive measurements are not in dependent, and we do not wish to overinterpret the results, it is clear that paired inter-dimensional correlations are rather systematically higher in the female.

Further grouping the correlations by measurement, as in table 1 , the sex differences are again systematic. For 16 measurements (13 of them direct and 3 derived), the females were systematically higher in grouped values of $r$, without ex- ception. Whether for mandibular height (largest mean difference between the sexes) or corrected browridge thickness (smallest difference between mean values of $r$ ) and whether computing simple mean values of $r$ directly or after the use of $\mathrm{Z}$ transforms, the results are unequivocal. Intra-individual, inter-dimensional communalities are higher for females of $\mathrm{Ma}$ caca nemestrina than for the males of the same genus and species.

As of now, a fully satisfactory genetic explanation for higher dimensional or developmental communalities in the female has not been adduced, either for prenatal or postnatal time. Clearly, this phenomenon exists for human embryos and fetuses, for postnatal development of median-income Ohio White children and for wild- 
TABLE 1

Sex differences in intra-individual dimensional communalities in Macac a nernestrina

\begin{tabular}{|c|c|c|c|c|c|c|}
\hline \multirow{2}{*}{ Dimension } & \multicolumn{3}{|c|}{ Communalities 1} & \multicolumn{3}{|c|}{ Communalities ${ }^{2}$} \\
\hline & 31 males & 30 females & $d^{3}$ & 31 males & 30 females & $d^{3}$ \\
\hline 1. Browridge thickness & 0.22 & 0.35 & 0.13 & 0.31 & 0.42 & 0.11 \\
\hline 2. Thickness of frontal & 0.24 & 0.42 & 0.18 & 0.26 & 0.44 & 0.18 \\
\hline 3. Ridge minus frontal & 0.18 & 0.27 & 0.09 & 0.32 & 0.36 & 0.04 \\
\hline 4. Internal cranial length & 0.17 & 0.33 & 0.16 & 0.25 & 0.34 & 0.09 \\
\hline 5. Internal cranial height & 0.04 & 0.10 & 0.06 & 0.06 & 0.10 & 0.04 \\
\hline 6. Mandibular length & 0.37 & 0.51 & 0.14 & 0.38 & 0.52 & 0.14 \\
\hline 7. Ramus height & 0.32 & 0.39 & 0.07 & 0.33 & 0.40 & 0.07 \\
\hline 8. Ramus width & 0.24 & 0.36 & 0.12 & 0.25 & 0.37 & 0.12 \\
\hline 9. Mandibular body length & 0.26 & 0.46 & 0.20 & 0.31 & 0.46 & 0.15 \\
\hline 10. Mandibular height at $P_{4} M_{1}$ & 0.23 & 0.45 & 0.22 & 0.25 & 0.46 & $0: 21$ \\
\hline 11. Symphyseal height & 0.12 & 0.28 & 0.16 & 0.12 & 0.32 & 0.20 \\
\hline 12. Basal bone height & 0.16 & 0.31 & 0.15 & 0.18 & 0.34 & 0.16 \\
\hline 13. Dental height & 0.39 & 0.47 & 0.08 & 0.40 & 0.49 & 0.09 \\
\hline 14. Total tooth height & 0.12 & 0.34 & 0.22 & 0.15 & 0.38 & 0.23 \\
\hline 15. Crown height & 0.04 & 0.14 & 0.18 & 0.01 & 0.15 & 0.14 \\
\hline 16. Root height & 0.13 & 0.29 & 0,16 & 0.16 & 0.33 & 0.17 \\
\hline Mean & 0.20 & 0.34 & 0.15 & 0.31 & 0.42 & 0.11 \\
\hline
\end{tabular}

1 Mean $r$.

2 Mean $r$ calculated from the mean $\mathrm{Z}$ transform of $r$

isex difference in $r$

collected adult pig-tailed monkeys. It is not a chance reflection of prenatal selection or of collection in Asia and subsequent survival under colony conditions. Mittwoch's work on the genetics of sex differentiation (73) does not provide a working answer.

The fact that intra-individual developmental and dimensional correlations are systematically higher in the female than the male and the fact that inter-age di-

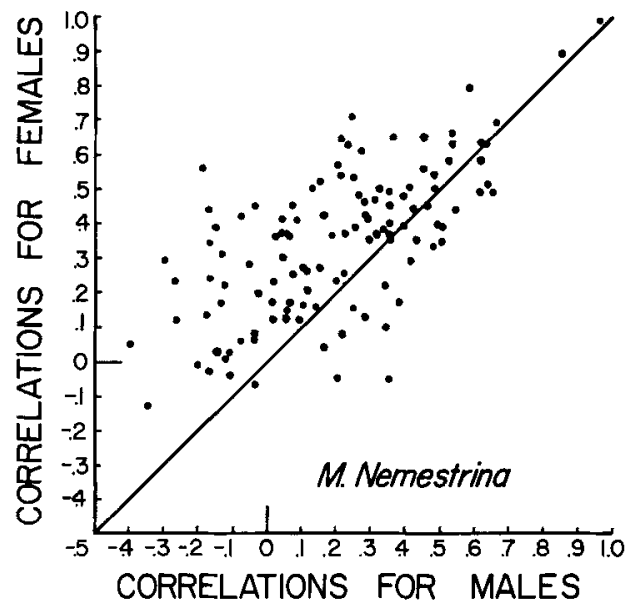

Fig. 2 Values of cranio-facial correlations involving Macaca nemestrina males (abcissa) and fernales (ordinate) showing the tendency toward greater values of $r$ in the fernales. mensional and developmental correlations are also higher in the XX, may be attributed to the greater amount of coded information present in the paired $\mathrm{X}$ chromo somes in the female and to what we have previously termed "informational redundancy." It has also been suggested that higher intra-individual correlations in the female might be due to greater dimensional variance in the female, indicative of a "dosage effect," such as we have previously reported for some developmental events (Garn and McCreery, '70). However, the present dimensional data for cranial, endocranial, mandibular and dental components show no evidence for greater female variance, whether measured as $\sigma^{2}$ or, size-corrected, as the coefficient of variation (C.V.).

This paper is the fourth of a series showing higher mean inter-correlations in the female than in the male, and including prenatal development, postnatal crown size dimensions, ossification timing and cranio-facial dimensions. We have, moreover, similar data other than parameters of growth and development, including behavioral development, where intra-girl correlations are higher than intra-boy correlations. While we have as yet no acceptable genetic explanation, the facts here reported may be extended into a major generalization. During growth and devel- 
opment dimensional and developmental communalities are systematically higher in the female in man and monkey alike.

\section{ACKNOWLEDGMENTS}

This study was supported in part by grants DE 03610 and DE 02918, National Institute of Dental Research. Appreciation is extended to Ken Guire and Sara Stinson for their help in data analysis and to Dixie L. Farquharson for her assistance in manuscript preparation.

\section{LITERATURE CITED}

Burdi, A. R., S. M. Garn and W. J. Babler 1974 Greater female communalities in prenatal hand and dental development. Arch. Oral Biol., 19: $461-466$.

Garn, S. M., A. B. Lewis, R. S. Kerewsky and K. Jegart 1965 Sex differences in intraindividual tooth-size communalities. J. Dent. Res., 44 $476-479$

Garn, S. M., and L. D. McCreery 1970 Variability of postnatal ossification timing and evi dence for a "dosage" effect. Am. J. Phys. Anthrop., 32: 139-144.

Garn. S. M., and C. G. Rohmann 1966a Com munalities in the ossification timing of the growing foot. Am. J. Phys. Anthrop., 24:45-49.

- $1966 \mathrm{~b}$ Interaction of nutrition and ge netics in the timing of growth and development. Pediat. Clin. N. Amer., 13: 353-379.

Garn, S. M., C. G. Rohmann, T. Blumenthal and C. S. Kaplan 1966 Developmental commu nalities of homologous and non-homologous body joints. Am. J. Phys. Anthrop., 25: 147-151.

Garn, S. M. C. G. Rohmann, T. Blumenthal and F. N. Silverman 1967 Ossification communalities of the hand and other body parts: their implication to skeletal assessment. Am. J. Phys. Anthrop., 27: 75-82.

Mittwoch, U. 1973 Genetics of Sex Differentiation. Academic Press, New York. 